\title{
A service for the adult asthmatic
}

\author{
B DAVIS, P M GETT,* AND E SHERWOOD JONES
}

\begin{abstract}
From the Clinical Research Laboratory and Intensive Care Unit, Whiston Hospital, Prescot, Merseyside
\end{abstract}

ABSTRACT A service for 300 adult asthmatics is described. Since the service was started in 1970 only one death has occurred and this patient failed to comply with treatment or advice. Two patients required intermittent positive pressure ventilation. The success of the service is founded on two facts. Firstly, the natural history of life-threatening asthma usually allowed time to change treatment at home or in a clinic and this prevented the development of the severe grades. Secondly, the great majority of asthmatics could be taught how to recognise worsening of their asthma and to communicate with a doctor who then changed the treatment. An essential feature of the service is that the patients had at all times easy access to a doctor with appropriate knowledge and attitudes.

Despite advances in treatment, approximately 1500 patients in Britain die from asthma each year and a far greater number suffer severe disabilities. Attacks of acute severe asthma (status asthmaticus) usually respond to oxygen therapy, rehydration, and drugs. When these measures fail, intermittent positive pressure ventilation (IPPV) usually succeeds. ${ }^{1}$ The disabilities of dyspnoea, cough, and disturbed sleep have been reduced by modern drug therapy. In 1970 we established an asthma service with the aim of reducing death to the minimum without recourse to IPPV.

The success of the service was founded on two related findings, both obtained in this unit. First, we found from a study of the time-course or natural history of acute severe asthma, that most patients reached a life-threatening stage of asthma after many hours or days. To study the natural history of asthmatic attacks, we graded the severity of the asthma in 65 attacks according to the disability caused by breathlessness or fatigue as shown in table $1 .^{2}$ Through questioning of patients who had recovered from a severe acute attack of asthma showed that the majority of lifethreatening attacks evolved over days or even weeks as shown in table 2. All the patients reached grade 3 asthma, but in doing so they spent several days in the less severe grades. Thus, with rare exceptions, there was enough time to treat

Address for reprint requests: Dr E Sherwood Jones, Intensive Care Unit, Whiston Hospital, Prescot, Merseyside L35 5DR.

*Dr Gett died in 1974. the worsening asthma, and avoid a life-threatening attack (grades 3 and 4). The second finding concerned the training of the asthmatic patient. We found that we could train almost all of our patients to recognise a worsening of their disease,

\section{Table 1 Method for grading the severity of asthma}

\begin{tabular}{ll}
\hline Grade & Description \\
\hline 1A & $\begin{array}{l}\text { You are carrying out your job or housework with } \\
\text { moderate difficulty. Sleep occasionally disturbed. } \\
\text { You are carrying out your job or housework with great } \\
\text { difficulty. More frequently disturbed sleep but the asthma } \\
\text { is not relieved by an inhaler. } \\
\text { You are confined to a chair or bed, but are able to get up } \\
\text { with moderate difficulty to make a cup of tea. Your sleep } \\
\text { is disturbed by asthma which is notrelieved by the inhaler. }\end{array}$ \\
2B & $\begin{array}{l}\text { You are confined to a chair or bed but are able to get up } \\
\text { with great difficulty to make a cup of tea. You are unable } \\
\text { to sleep. Your pulse rate is } 120 \text { per minute or more. } \\
\text { You are totally confined to a chair or bed. Your pulse } \\
\text { rate is } 120 \text { per minute or more. }\end{array}$ \\
& $\begin{array}{l}\text { You are completely exhausted. Your pulse rate is } 120 \text { per } \\
\text { minute or more. }\end{array}$
\end{tabular}

Table 2 Natural history of severe acute asthma: analysis of 65 admissions

\begin{tabular}{lll}
\hline & \multicolumn{2}{l}{ Time in days } \\
\cline { 2 - 3 } & Mean & $S D$ \\
\hline Onset to admission & 15.5 & 1.9 \\
Duration of each grade & & \\
1 & 12.1 & 1.8 \\
2 & 7.5 & 1.2 \\
3 & 1.6 & 0.5 \\
\hline
\end{tabular}


to grade the asthma according to our criteria, and to communicate the information to a doctor. Thus, changes could be made in the patient's treatment early in an attack. This has resulted in less disability, fewer admissions to hospital, and far fewer attacks of life-threatening asthma.

\section{The service}

The service consisted of four related components: a register, a clinic, a reserved hospital bed, and an intensive care unit. Information about each patient's asthma was entered in a register and was quickly available at any time. Patients were enrolled on the register from one of two sourcesmost were patients newly admitted to hospital and the rest were referred to our weekly asthma clinic which lasted two to three hours. The objectives of the clinic were four. First we aimed to reduce disability to a minimum by the appropriate use of bronchodilators, inhaled or oral steroids and by avoiding identified extrinsic factors and, when possible, by hyposensitisation. The use of drugs was revised to follow current medical practice. Secondly we wanted to ensure that medication was taken correctly. We reminded the patients repeatedly of the importance of taking prophylactic drugs regularly. The patient's technique for using inhaled drugs was checked by a doctor in the clinic. Thirdly we attempted to teach our grading system and the significance of worsening asthma. We reinforced verbal instructions by giving each patient written directions. Finally we trained the patients to communicate with a doctor promptly when their asthma was worsening. The purpose of this doctor-patient consultation was to enable a doctor to change existing treatment and thus halt deterioration. A doctor could make this decision in the asthma clinic, in other parts of a hospital, in a health centre, or over the telephone. The pathways of communication and the decisions made are shown as a flow diagram (fig). For the service to be effective, rapid communication and prompt medical assessment had to be available day or night every day-an "open door" arrangement.

Each year a few patients on the register required admission to hospital. An integral part of the asthma service was to guarantee that a bed was always available in order to expedite admission.

The following criteria were used for admission to the intensive care unit: grade 2B asthma for more than eight hours; grades 3 or 4 asthma. In the intensive care unit the patient was under

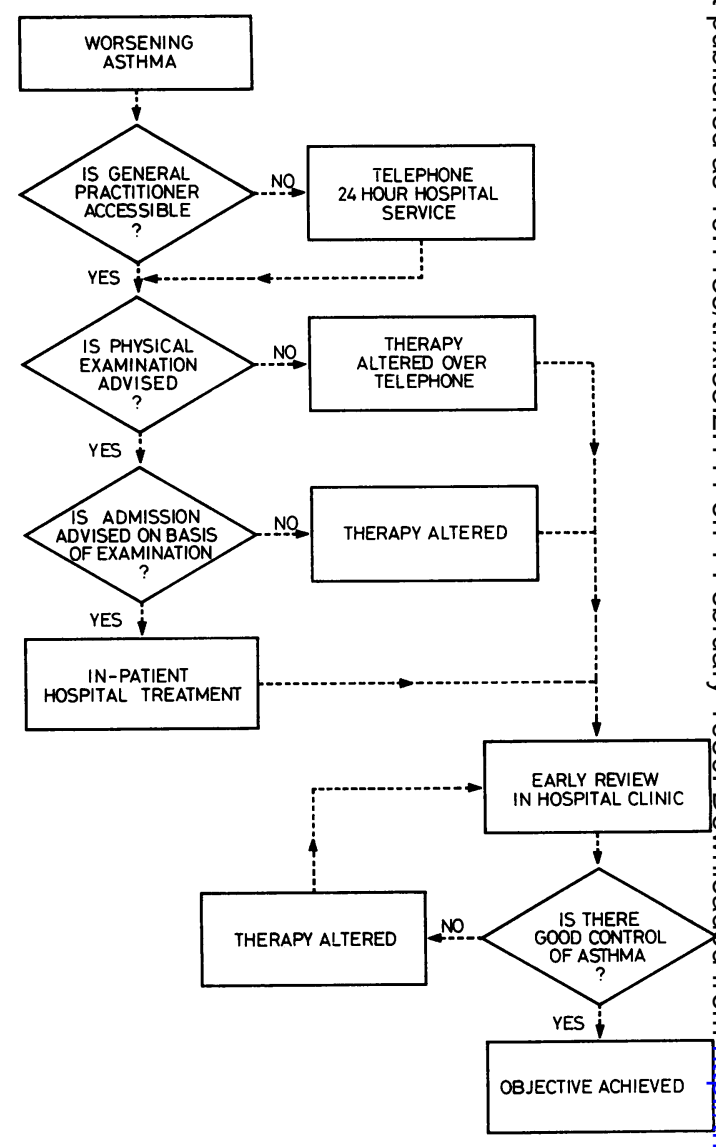

Figure Possible actions to be taken in worsening asthma. Diagram constructed by $\operatorname{Dr} A R$ Luksza.

continuous observation by specifically traine nurses and should IPPV become necessary this could be started long before respiratory or cardiaç arrest occurred. The techniques required were evolved in this unit. ${ }^{3}$

\section{Results}

Only one out of 300 patients on our register die from asthma. This patient was a teenage girl wh $\mathcal{g}^{\circ}$ repeatedly ignored advice and failed to attene the clinic. Her "death wish" was recorded in ouf notes 12 months before her death in 1975. Tw other patients died, one from pulmonary embolism (confirmed by post-mortem) and one after af operation. Two registered asthmatics require IPPV and both survived. Both patients confesse $\$$ that they had recognised the deterioration of theie asthma and that they had failed to communicate with the service. Admissions to hospital average 
20 per year. In each patient requiring admission the natural history followed that already described (table 2) and the patients recognised retrospectively that admission to hospital could have been avoided. Emergency calls by patients to the hospital were less than one a week but the patients never misused the service. Over $90 \%$ of the patients kept their clinic appointments.

\section{Discussion}

In 1970 we started an asthma service which now provides care for 300 patients on our register. Through the service we trained the patients to recognise worsening asthma by using a grading system and to communicate with a trained doctor early in the development of an attack so that he could prescribe appropriate treatment. We believe that the service has reduced disability, admissions to hospital, and life-threatening attacks of asthma. However, we have no controlled studies to support this belief. Nevertheless, while only one patient on our register has died from asthma since 1970, 23 patients in this area, but not on our register, were reported to have died from asthma between 1974 and $1977 .{ }^{4}$ Our service might have prevented some of these deaths.

Life-threatening asthma has contrasting natural histories. In our patients the disease usually evolved over days or weeks but in an important minority the severe grades were reached in hours. We believe that slowly developing asthma has not been adequately studied in contrast to that which evolves quickly. Descriptions of the latter are found frequently in the literature-for example, "the fatal attack was typically short"5; "risk of death should rarely be associated with the severity of the attack and may not be related to it" 6 . "death from asthma may occur quickly and almost without warning"7; "overwhelming asthma develops within a very short period of time, usually within one or two hours, often less". 8

The service was derived from our studies of the natural history of severe asthma and by recognising our patients' ability to take some responsi- bility for their own care. One feature of the service is an "open door" policy which $\mathrm{Dr}$ DA Williams started in Cardiff in the 1950s (personal communication). This requires that the asthmatic should at all times have easy access to a doctor who can assess and treat the disease, has the appropriate attitudes to asthma, and a sense of obligation to the patient.

The Whiston asthma service was developed in a general hospital with an intensive care unit. However, no specialised knowledge or equipment were required to run the service. A similar service could be run by a group of general practitioners from a health centre if they adopted an "open door" principle and the criteria for admission to hospital were jointly agreed. We hope that the widespread application of the principles described will reduce both deaths and disabilities drastically.

Research on asthma was supported by grants from Prescot Rotary, the Whiston Asthma Fund, the Asthma Research Council, and the Research Committee of the Mersey Regional Health Authority.

\section{References}

1 Jones ES, Riding WD, Asthma. In: Jones ES, ed. Essential intensive care. Lancaster: MTP Press, 1978: 303-15.

2 Jones ES. The intensive therapy of asthma. Proc R Soc Med 1971; 64:1151-2.

3 Riding WD, Ambiavagar M. Resuscitation of the moribund asthmatic. Postgrad Med J 1967; 43: $234-43$.

4 Office of Population Censuses and Surveys. SD25. 1974197519761977.

5 Macdonald JB, Seaton A, Williams DA. Asthma deaths in Cardiff 1963-74: 90 deaths outside hospital. Br Med J 1976; 1:1493-5.

6 Hetzel MR, Clark TJH, Branthwaite MA. Asthma: analysis of sudden deaths and ventilatory arrests in hospital. Br Med J 1977; 1:808-11.

7 Crompton GK, Grant IWB. Edinburgh emergency asthma admission service. Br Med J 1975; 4:680-2.

8 Howard P. Management of severe acute asthma. Br Med J 1978; 1:1138. 